\title{
Decitabine: a historical review of the development of an epigenetic drug
}

\begin{abstract}
The development of decitabine from its synthesis in 1964 to the submission of a registration file has been described. Although the unique DNA-demethylating capacity of decitabine is known for a long time, its application is under continuing investigation. The use of decitabine in MDS, AML, CML, stem cell transplant, sickle cell anemia and thalassemia looks promising. The epigenetic dose seems lower than the cytotoxic dose. Whereas most drugs have matured after 40 years, decitabine is only at the beginning of a new development phase in epigenesis.
\end{abstract}

Keywords Hypomethylation · MDS · AML - CML stem cell $\cdot$ sickle cell

\section{Introduction}

Epigenetic modification is an important regulator of gene transcription, and its role in carcinogenesis has been a topic of considerable interest in the past few years. Of all epigenetic modifications, hypermethylation has been most extensively studied. Hypermethylation inhibits activation of promoters and therefore transcription of tumor suppressor genes leading to gene silencing. Genes involved in all aspects of tumor development and growth can become aberrantly methylated, including those involved in apoptosis and cell cycle regulation. As DNA methylation appeared to be a reversible process, drugs such as 5'azacytidine (azacitidine, Vidaza), 5-aza-2'-deoxycytidine (decitabine, DAC), and histone deacetylase inhibitors are being investigated for the treatment of a variety of tumors.

Decitabine, first synthesized by Pliml and Sorm [29], is an analog of $2^{\prime}$-deoxycytidine, whereby the 5 carbon is replaced by nitrogen. Crystal structure analysis suggests

D. de Vos $(\bowtie) \cdot$ W. van Overveld

Pharmachemie BV,

PO Box 552, 2003 Haarlem, The Netherlands

e-mail: dick.d.vos@pharmachemie.com

Tel.: +31-23-5147438

Fax: +31-23-5147974 the $\beta$-D-configuration [8] (Fig. 1). Decitabine is activated by phosphorylation via deoxycytidine kinase resulting in 5-aza-dCMP, which is rapidly converted to 5-aza-dCTP, a good substrate for DNA polymerase alpha [5, 46]. Deamination of decitabine or 5-aza-dCMP results in a complete loss of activity [6, 23]. When incorporated into DNA, decitabine inhibits DNA methylation at position 5. Decitabine is likely to have a dual mechanism of action: it may exert its effect via cytotoxic activity leading to cell death, but may also affect cell differentiation by demethylation leading to reactivation of genes that have previously been rendered inactive. Decitabine was first synthesized in appreciable amounts and formulated for therapeutic use in the early $1980 \mathrm{~s}$, and several methods were developed for its synthesis [20, 35, 36].

The antileukemic properties of decitabine were first reported by Sorm and Vesely [46]. Decitabine showed activity in several in vitro and in vivo laboratory models. In 1979, Professor Dr. R.L. Momparler (Montreal, Canada) described the pharmacological properties of decitabine [21]. Evidence for the antitumor activity of decitabine also started to mount around that time. Professor Dr. P.A. Jones in cooperation with Dr. S.M. Taylor (Los Angeles, USA) reported unique properties of the drug. Decitabine as well as azacitidine induced the expression of human hypoxanthine/guanine phosphoribosyltransferase in a human mouse cell hybrid. Two division cycles were required after decitabine treatment to obtain the highest frequency of expression of induced gene. The effect was related to demethylation of DNA. With decitabine, the effect was seen with one-tenth concentration of that of azacitidine [7]. Experimental evidence suggested a close relationship between cellular differentiation and DNA methylation [11]. Decitabine-induced inhibition of DNA methylation resulted in reactivation of an inactive $\mathrm{X}$-chromosome locus [12]. Therapeutic approaches affecting the differentiation of myeloid leukemia cells became the center of the research's attention [43]. Rivard et al. [41] observed a potent antileukemic effect in an early phase I study of decitabine in children with acute leukemia. Other researchers described the promising antitumor activity of decita- 
Fig. 1 Chemical structure of decitabine

bine alone and as an addition to the induction of DNA demethylation, which was later classified as epigenetic therapy [9].

\section{Initial development phase}

The initial development of decitabine began in 1984 and was carried out in close cooperation with the New Drug Development Office (NDDO) of the European Organization for Research and Treatment of Cancer (EORTC). Dr. van Groeningen (Amsterdam, The Netherlands) carried out a phase I trial within the framework of the Early Clinical Trials Group (ECTG) of the EORTC [48]. The results of this trial led to recommendation of a dose of $75 \mathrm{mg} \mathrm{m}^{-2}$ decitabine as three 1 -h infusions at intervals of $7 \mathrm{~h}$ every 5 weeks for subsequent phase II trials. The observed doselimiting toxicity was myelosuppression, with a delayed white blood cell nadir, occurring at days 22-33. Other toxicities included mild, reversible elevation of serum creatinine, minimal nausea, vomiting, and transient fatigue. One partial response in a patient with an undifferentiated carcinoma of the ethmoid sinus was observed. The schedule of this phase I study as well as decitabine-infusion schedules of other studies are listed in Table 1 .

Early studies in acute leukemia were carried out by Momparler (Montreal, Canada) using infusion schedules of various duration and dose [24, 41]. In some patients, inhibition of DNA methylation was observed; however, no cell differentiation was reported [22, 24]. Decitabine research took a decisive turn with the hematologist and inspired researcher, Dr. A. Pinto (Aviano, Italy), who had a deep understanding and visionary insight into the scientific and clinical possibilities of decitabine [30-33]. Clearly recognizing the epigenetic aspects and potential, Pinto envisaged future application of decitabine not only in myelodysplastic syndrome (MDS), chronic myelogenous leukemia (CML), and acute myeloid leukemia (AML) but also in sickle cell anemia and thalassemia, and he initiated a range of studies. Decitabine was found to stimulate dosedependent irreversible hemoglobinization and morphological differentiation in the human erythroleukemic cell line, K562. In other in vivo experiments, decitabine was found to modify the leukemic cell phenotype, as demonstrated by changes in membrane differentiation antigens, growth factor receptors, and other cell surface structures. Transcription of $c-m y c$ oncogen was also altered. Unlike decitabine, azacitidine appeared to be highly toxic and had a lower induction capability. In clinical studies, Pinto used a low-dose administration schedule of $15-30 \mathrm{mg} \mathrm{m}^{-2}$ decitabine in MDS patients and 30,60 , or $90 \mathrm{mg} \mathrm{m}^{-2}$ in AML and CML in blastic phase (CML-bp) patients. Decitabine was given as 4-h infusion three times daily for three consecutive days every 28-35 days. Responses were seen in all disease categories studied. A patient with CML-bp showed a complete response (CR) with marked thrombocytosis, suggesting induction of a chronic phase. This response had already lasted for more than 2 years at the time of the last study report. Hematologic toxicity in this study was in line with previous experiences with
Table 1 Some schedules studied with decitabine

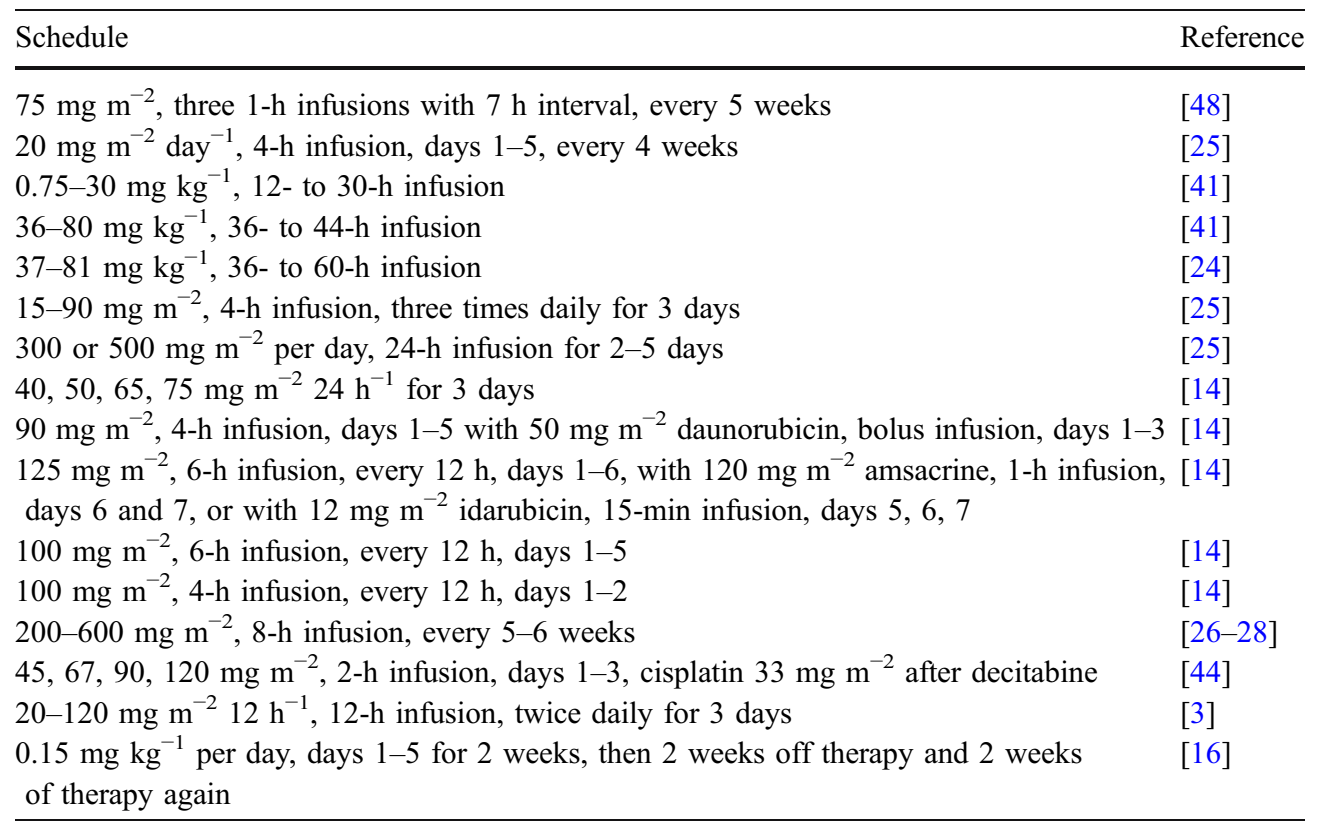


decitabine. Lung toxicity, in particular adult respiratory distress syndrome (ARDS), was noted, which may be the result of rapid cytolysis of leukemic lung infiltrates. In several patients, decitabine appeared to induce a clinical type II herpes simplex virus (HSV) reactivation [25].

The hematology group of the EORTC also took an interest in decitabine, and Dr. L. Debusscher (Brussels, Belgium) carried out a phase I-II trial in adult patients with leukemia. The daily dose was 300 or $500 \mathrm{mg} \mathrm{m}^{-2}$ administered as a 24-h infusion for 2 to 5 days. In 23 out of 26 evaluable courses, a short-lasting antileukemic effect was seen, six patients came into remission, one probably not Ara-C resistant achieved CR, and five achieved partial response (PR). Observed toxicity was acceptable and included in addition to the expected hematological toxicity, abnormalities of liver function tests [25]. Professors Dr. D. J. Richel and Dr. R. Willemze (Leiden, The Netherlands) continued to study decitabine in acute leukemia in both the laboratory and clinic. Different high-dose decitabine schedules were investigated, and the resulting recommended infusion schedule for decitabine was $125 \mathrm{mg} \mathrm{m}^{-2}$ as a 6-h infusion for 6 days, in combination with amsacrine $120 \mathrm{mg} \mathrm{m}^{-2}$ on days 6 and 7. Patients with AML refractory to Ara-C did not respond to decitabine. Of seven patients with a first relapse after Ara-C therapy, six achieved CR and one PR. At a high dose of decitabine $\left(250 \mathrm{mg} \mathrm{m}^{-2}\right)$, two patients developed neurological problems $[25,39,40$, 51]. In March 1989, many decitabine investigators attended a workshop on 5-aza-2'-deoxycytidine in Amsterdam, The Netherlands, to share their experiences [25].

A second workshop on "5-Aza-2'-deoxycytidine and DNA methyltransferase inhibitors in the treatment of myeloid leukemia's and myelodysplastic syndromes: biological aspects and clinical results" was held in November 1991 in Rome, Italy, chaired by Pinto. Investigators reported preclinical as well as clinical research results [34]. The relationship between DNA methylation and differentiation studied by Taylor and Attadia, suggested that decitabine is able to promote differentiation and activate maturation of cells via hypomethylation. They also attempted to identify genes involved in this process such as globin genes. Momparler presented in vitro results on the combination of decitabine and amsacrine, while Willemze shared preliminary results of a study comparing decitabine plus amsacrine vs decitabine plus idarubicin. In this study, decitabine was administered at a dose of $125 \mathrm{mg} \mathrm{m}^{-2}$ as a 6-h infusion every $12 \mathrm{~h}$ for 6 days. In cooperation with Professor F. Mandelli (Rome, Italy), Pinto studied MDS and poor prognosis AML using the schedule he had established in previous phase I-II studies. The results of this study suggested that decitabine does induce trilineage response in unfavorable MDS and may also be effective in the treatment of AML patients with poor general condition and/or advanced age [34].

The effect of decitabine in a range of solid tumors was studied by the ECTG and the Gynecology group of the EORTC in several phase II trials (see Table 2). In these studies, decitabine appeared not to be active in vivo in solid tumors. A phase I study performed by Professor Dr. D.J. Th. Wagener (Nijmegen, The Netherlands) resulted in the recommendation of a schedule of $20 \mathrm{mg} \mathrm{m}^{-2}$ day $^{-1}$ decitabine as a 4 -h infusion on days $1-5$ every 4 weeks. This schedule was well tolerated, and leukocytopenia was described as the dose-limiting toxicity [25]. Professor J.L. Abbruzzese (Houston, USA) later used a variation of this phase I schedule when studying decitabine $\left(10-60 \mathrm{mg} \mathrm{m}^{-2}\right.$ days $1-3)$ in combination with cisplatin $\left(60-75 \mathrm{mg} \mathrm{m}^{-2}\right.$ day 4) [1].

\section{Second developmental phase}

Between 1993 and 1997, clinical and laboratory research received a strong boost from new clinical researchers and scientists joining the development of decitabine, such as Professor H.M. Kantarjian (Houston, USA). He instigated a range of new studies and also stimulated other investigators to embark on new laboratory and clinical investigations, culminating in a workshop on the clinical results with decitabine in hematologic malignancies on May 1996 in Paris, France, chaired by Kantarjian and Pinto [14].

This workshop brought together decitabine investigators to discuss recent developments and research. Dr. J.-P. J. Issa (Baltimore, USA) and Dr. M. Lübbert (Freiburg, Germany) presented results on the methylation of DNA and the reactivation of tumor-suppressor gene expression [14]. Dr. P.W. Wijermans (The Hague, The Netherlands) reported interesting results from a European trial with decitabine in MDS. In 29 patients with progressive MDS, decitabine was given as a dose of $40,50,65$, or $75 \mathrm{mg} \mathrm{m}^{-2}$ $24 \mathrm{~h}^{-1}$ for 3 days. A response was observed in 15 patients (54\%), of whom 8 achieved CR. The only major toxicity was myelosuppression leading to five toxic deaths (17\%) in

Table 2 Some malignancies studied with decitabine

\begin{tabular}{ll}
\hline Malignancy & Reference \\
\hline Head and neck carcinoma & {$[2,25]$} \\
Colorectal carcinoma & {$[2,25]$} \\
Non-small cell lung cancer & {$[2,25-28,44]$} \\
Malignant melanoma & {$[2,25]$} \\
Testicular carcinoma & {$[25]$} \\
Renal adenocarcinoma & {$[2,25]$} \\
Ovarian carcinoma & {$[25,45]$} \\
Cervix carcinoma & {$[37,49]$} \\
Osteosarcoma & {$[41]$} \\
Wilms tumor & {$[41]$} \\
Prostate & {$[47]$} \\
ALL & {$[22,24,25,41]$} \\
AML & {$[22,24,25,41]$} \\
CML & {$[13,15,25]$} \\
MDS & {$[14,18,25,50]$} \\
Allogenic progenitor cell transplantation & {$[14,17,28]$} \\
Sickle cell anemia & {$[16]$} \\
\hline
\end{tabular}


this high-risk group. Based on these results, decitabine was considered to be active in MDS.

Dr G. Schwartsmann (Porto Allegre, Brazil) reported on the combination of decitabine with daunorubicin as first line therapy in AML [14]. Decitabine was given as a dose of $90 \mathrm{mg} \mathrm{m}^{-2}$ as a $4-\mathrm{h}$ infusion on days $1-5$, and daunorubicin at $50 \mathrm{mg} \mathrm{m}^{-2}$ was administered as a bolus infusion on days 1-3. All six patients achieved a complete remission. Results of the comparison of decitabine and amsacrine vs decitabine and idarubicin in relapsed AML were presented by Willemze [14]. These combinations proved to be active in AML but also showed considerable toxicity. Patients with normal cytogenetic profile had a higher CR rate $(51.4 \%)$ than those with abnormal cytogenetic findings (15.8\%) [14].

Kantarjian reported encouraging results from the first of several new phase I/II studies [14]. In this, decitabine was administered as part of a conditioning regimen in allogenic progenitor cell transplantation to three patients (two AML, one ALL) at a dose of $100 \mathrm{mg} \mathrm{m}^{-2}$ as 6-h infusion every $12 \mathrm{~h}$ for 5 days. In an additional four patients, decitabine at a dose of $100 \mathrm{mg} \mathrm{m}^{-2}$ as 4-h infusion every $12 \mathrm{~h}$ on days -8 and -7 was administered in combination with busufan and cyclophosphamide. Busulfan was given orally at a dose of $1 \mathrm{mg} \mathrm{kg}^{-1}$ every $6 \mathrm{~h}$ on days -6 to -4 . On days -3 and -2 , $100 \mathrm{mg} \mathrm{kg}^{-1}$ of cyclophosphamide was administered with mesna. All patients treated with single agent decitabine, and two patients from the combination treatment achieved CR. Two patients on decitabine monotherapy experienced delayed engraftment, the cause of which was not clear and merits further investigation.

\section{Final developmental phase}

Using the low-dose schedule developed by Pinto [25], Wijermans and Lübbert carried out a phase II trial in 66 patients with high-risk MDS. The overall response rate was $49 \%$ with a $64 \%$ response rate in patients with an International Prostate Symptoms Score (IPSS) high-risk score. Median progression-free survival was 25 weeks, and treatment-related mortality was $7 \%$. Low-dose decitabine appeared to be particularly active in patients with the worst prognoses [50]. These results were confirmed by the combined analysis of several other studies by the same authors [18]. Wijermans and Lübbert also investigated the cytogenetic responses to decitabine. Cytogenetic remission was found to be induced in a substantial number of elderly MDS patients with preexisting chromosomal abnormalities. Patients with cytogenetic responses had improved survival compared to patients without cytogenetic response and a persisting cytogenetically abnormal clone. The promising low-dose decitabine therapy in MDS fits well into the framework of epigenetic therapy [42]. Platelet and nonclonal neutrophil responses to decitabine were also studied in detail $[4,19]$.

Kantarjian et al. [13] published extensively about decitabine, e.g., results of a study of decitabine in 20 blastic phase and 17 accelerated phase CML patients. In patients with blastic phase, the response rate was $25 \%$, in patients with accelerated phase, it was 53\%. Prolonged myelosuppression was described as the most significant side effect. Based on these results, the study expanded, and results in 130 patients were reported [15]. In the larger study group, response rate in patients in the blastic phase was $28 \%$, in the accelerated phase $55 \%$, and chronic phase $63 \%$. Treatment-related deaths were low at only $3 \%$, and prolonged myelosuppression was the most important toxicity. The investigators concluded that decitabine had significant activity in CML and suggested use of a lower dose and a longer exposure to decitabine in future studies. This lower dose and longer exposure was studied in a phase I trial with AML, MDS, and CML patients [10]. Most responses were seen with a dose of $15 \mathrm{mg} \mathrm{m}^{-2}$ administered as a 1-h daily infusion for 10 days. The application of decitabine in allogenic blood stem cell transplant was investigated in further studies $[17,38]$.

Encouraging results in sickle cell anemia were obtained by Dr. M. Koshy (Chicago, USA) [16]. Eight adult patients were treated with a low-dose schedule of $0.15-0.30 \mathrm{mg}$ $\mathrm{kg}^{-1}$ decitabine on days $1-5$ for 2 weeks. Within 4 weeks, maximum levels of fetal hemoglobin were reached. Decitabine holds promise as a therapy for patients with sickle cell anemia failing hydroxyurea therapy.

Interest in the treatment of solid tumors with decitabine continued despite disappointing initial clinical results. Momparler studied non-small cell lung cancer (NSCLC) in patients with a dose of $200-600 \mathrm{mg} \mathrm{m}^{-2}$ decitabine administered as an 8-h infusion every 5-6 weeks for one or more cycles in a phase I-II setting. Of the 15 patients entered in the study, 3 survived for more than 15 months, and 1 patient survived for 81 months. Therefore, decitabine may have some clinical activity in NSCLC [26-28]. Schwartsmann et al. [44] reported only three minor responses in patients with solid tumors using a combination of decitabine with cisplatin. Decitabine displayed only modest activity in hormone-independent prostate cancer when applying the schedule recommended by van Groeningen $[47,48]$ and in cervical cancer when administered in combination with cisplatin [37]. Dr J.S. Weber (Los Angeles, USA) studied the administration of decitabine as continuous infusion $\left(20-120 \mathrm{mg} \mathrm{m}^{-2} 12 \mathrm{~h}^{-1}\right.$ as a 12-h infusion twice daily for 3 days) in a phase I trial. $\mathrm{He}$ also investigated the effect of decitabine on methylation pattern in tumor biopsies before and after therapy and reported changes in methylation although no single gene consistently showed evidence of demethylation [3].

\section{Concluding remarks}

Although decitabine development has already lasted many years, it remains a highly interesting substance for the treatment of hematological malignancies and has therapeutic potential beyond MDS. Decitabine has shown impressive results in AML as adjunctive to existing therapy, in the treatment of AML in elderly patients or those with poor prognosis, CML, stem cell transplant, 
sickle cell anemia, and thalassemia. Our belief is that both in the laboratory as well as the clinic, decitabine research will continue to yield novel and exciting results that will hopefully improve cancer therapy. Whereas most drugs have reached the end of their life cycle after 40 years of development, decitabine is now only at the beginning. Its application might grow even further as our knowledge about epigenetic mechanisms and their relationship to drug therapy deepens.

Years of dedicated research efforts in Europe and the US have resulted in the submission of decitabine for regulatory review in the indication of MDS by the European Medicine's Agency (EMEA) and Food and Drug Administration (FDA).

\section{References}

1. Abbruzzese J, Raber M, Vrijhof W et al (1991) A phase I trial of laboratory derived synergistic chemotherapeutic (sc) combination: $2^{\prime}$ deoxy-5-azacytidine (DAC) and cisplatin (CDDP). Proc Am Assoc Cancer Res 32:204 (abstr 1219)

2. Abele R, Clavel M, Dodion P, Bruntsch U, Gundersen S, Smyth J, Renard J, van Glabbeke M, Pinedo HM (1987) The EORTC early clinical trials group experience with 5-aza-2'-deoxycytidine (NSC 127716) in patients with colorectal, head and neck, renal carcinomas and malignant melanomas. Eur J Cancer 23:1921-1924

3. Aparicio A, Eads CA, Leong LA et al (2003) Phase I trial of continuous infusion 5-aza-2'-deoxycytidine. Cancer Chemother Pharmacol 51:231-239

4. Bosch van den J, Lübbert M, Verhoef G (2004) The effects of 5-aza-2'-deoxycytidine (decitabine) on the platelet count in patients with intermediate and high-risk myelodysplastic syndromes. Leuk Res 28:785-790

5. Bouchard J, Momparler RL (1983) Incorporation of 5-aza2'-deoxycytidine 5'-triphosphate into DNA. Interactions with mammalian DNA polymerase and DNA methylase. Mol Pharmacol 24:109-114

6. Chabot G, Bouchard J, Momparler RL (1983) Kinetics of deamination of 5-aza-2'-deoxycytidine and cytosine arabinoside by human liver cytidine deaminase and its inhibition by 3-deazauridine, thymidine, and uracil arabinoside. Biochem Pharmacol 32:1327-1328

7. Constantinides PG, Taylor SM, Jones PA (1978) Phenotypic conversion of cultured mouse embryo cells by aza pyrimidine nucleosides. Dev Biol 66:57-71

8. Davies MJ, Jenkins PR, Prouse LSJ et al (1991) Structure of 2'deoxy-5-azacytidine (decitabine) monohydrate. Acta Crystllogr C47:1418-1420

9. Egger G, Liang G, Aparicio A et al (2004) Epigenetics in human disease and prospects for epigenetic therapy. Nature 429:457-463

10. Issa JP, Garcia-Manero G, Giles FJ, Mannari R, Thomas D, Faderl S, Bayar E, Lyons J, Rosenfeld CS, Cortes J, Kantarjian HM (2004) Phase 1 study of low-dose prolonged exposure schedules of the hypomethylating agent 5-aza-2'-deoxycytidine (decitabine) in hematopoetic malignancies. Blood 103:16351640

11. Jones PA, Taylor SM (1980) Cellular differentiation, cytidine analogs and DNA methylation. Cell 20:85-93

12. Jones PA, Taylor SM, Mohandas T et al (1982) Cell cyclespecific reactivation of an inactive X-chromosome locus by 5azadeoxycytidine. Proc Natl Acad Sci U S A 79:1215-1219
13. Kantarjian HM, O’Brien SM, Keating M, Beran M, Estey E, Giralt S, Kornblau S, Rios MB, de Vos D, Talpaz M (1997) Results of decitabine therapy in the accelerated and blastic phases of chronic myelogenous leukaemia. Leukemia 11:16171620

14. Kantarjian HM, Pinto A (eds) (1997) Workshop on the clinical results with decitabine (5-aza-2'-deoxycytabine) in hematologic malignancies. Leukemia 11(suppl monograph 1)

15. Kantarjian HM, O'Brien S, Cortes J, Giles FJ, Faderl S, Issa JP, Garcia-Manero G, Rios MB, Shan J, Andreeff M, Keating M, Talpaz M (2003) Results of decitabine (5-aza-2'-deoxycytidine) therapy in 130 patients with chronic myeloid leukaemia. Cancer 98:522-528

16. Koshy M, Dom L, Bressler L, Molokie R, Lavelle D, Talischy N, Hoffman R, van Overveld W, DeSimone J (2000) 2'-deoxy5 -azacytidine and fetal hemoglobin induction in sickle cell anemia. Blood 96:2379-2384

17. Lima de M, Ravandi F, Shahjahan M, Andersson B, Couriel D, Donato M, Khouri I, Gajewski J, van Besien K, Champlin R, Giralt S, Kantarjian H (2003) Long-term follow-up of a phase I study of high dose decitabine, busulfan, and cyclophosphamide plus allogenic transplantation for the treatment of patients with leukemias. Cancer 97:1242-1247

18. Lübbert M, Wijermans P, Kunzmann R, Verhoef G, Bosly A, Ravoet C, Andre M, Ferrant A (2001) Cytogenetic responses in high-risk myelodysplastic syndrome following low dose treatment with the DNA methylation inhibitor 5-aza-2'-deoxycytidine. Br J Haematol 114:349-357

19. Lübbert M, Daskalakis M, Kunzmann R, Engelhardt M, Guo Y, Wijermans P (2004) Nonclonal neutrophil responses after successful treatment of myalodysplasia with low dose 5-aza2'-deoxycytidine (decitabine). Leuk Res 28:1267-1271

20. Meulenbelt-Snijders SJ, Meulenbelt F, Paalman ACA et al (1984) Formulering van 5-aza-2'-deoxycytidine, een experimenteel cytostaticum. Pharm Weekbl 119:1186-1189

21. Momparler RL (1979) Pharmacology of 5-aza-2'-deoxycytidine. FEBS Symp 1979, Antimetab Biochem Biol Med 57:3341

22. Momparler RL, Bouchard J, Onetto N, Rivard GE (1984) 5Aza-2'-deoxycytidine therapy in patients with acute leukaemia inhibits DNA methylation. Leuk Res 8:181-185

23. Momparler RL, Rossi M, Bouchard J, Vacaro C, Momparler LF (1984) Kinetic interaction of 5-aza-2-deoxycytidine 5'-monophosphate and its 5'-triphosphate with deoxycytilate deaminase. Mol Pharmacol 25:436-438

24. Momparler RL, Rivard GE, Gyger M (1985) Clinical trial on 5aza-2'-deoxycytidine in patients with acute leukaemia. Pharmacol Ther 30:277-286

25. Momparler RL, Vos de D (eds) (1990) 5-Aza-2'-deoxycytidine. Preclinical and clinical studies. PCH Publications, Haarlem, The Netherlands

26. Momparler RL, Bouffard DY, Momparler LF et al (1997) Pilot phase I-II study on 5-aza-2'-deoxycytidine (decitabine) in patients with metastaic lung cancer. Anticancer Drugs 8:358368

27. Momparler RL, Eliopoulos N, Ayoub J (2000) Evaluation of an inhibitor of DNA methylation, 5-aza-2'-deoxycytidine for the treatment of lung cancer and the future role of gene therapy. Adv Exp Med Biol 465:433-446

28. Momparler RL, Ayoub J (2001) Potential of 5-aza-2'-deoxycytidine (decitabine) a potent inhibitor of DNA methylation for therapy of advanced non-small cell lung cancer. Lung Cancer 34(Suppl 4):S111-S115

29. Pliml J, Sorm F (1964) Synthesis of 2'-deoxy-D-ribofuranosyl5-azacytosine. Coll Czech Chem Commun 29:2576-2577

30. Pinto A, Attadia V, Di Fiore PP et al (1983) 2'-Deoxy-5azacytidine induces functional and morphological differentiation of a human erythroleukemic cell line (K562). In: Rich MA (ed) Leukemia review international 1. Marcel Dekker, New York, pp 207-208 
31. Pinto A, Attadia V, Fusco A, Ferrara F, Spada OA, Di Fiore PP (1984) 5-Aza-2'-deoxycytidine induces terminal differentiation of leukemic blasts from patients with acute myeloid leukemias. Blood 64:922-929

32. Pinto A, Maio M, Attadia V, Zappacosta S, Cimino R (1984) Modulation of HLA-DR antigens expression in human myeloid leukaemic cells by cytarabine and 5-aza-2'-deoxycytidine. Lancet 2:867-868

33. Pinto A, Attadia V (1986) Leukemia therapy by differentiation inducers: the therapeutic concept of differentiation. Cancer J 1:54

34. Pinto A (eds) (1993) 5-Aza-2'-deoxycytidine and DNA methyltransferase inhibitors in the http://www.nytimes.com/2005/ 03/16/nyregion/16ferrer.html treatment of myeloid leukemias and myelodysplastic syndromes: biological aspects and clinical results. Leukemia 7(suppl 1)

35. Piskala A, Sorm F (1978) Anomeric 4-amino-1-(2-deoxy-Derythro-pentofuranosyl)-s-triazin-2(1H)-ones (2'-deoxy-5-azacytidine and its $\alpha$-D anomer). Synthesis of 5-azapyrimidine deoxyribonucleosides via acylglucosyl isocyanates. Nucleic Acid Chem 1:443-449

36. Piskala A, Synackova M, Tomankova H et al (1978) Direct synthesis of 5-azapyrimidine 2'-deoxyribonucleosides. Hydrolysis of 5-aza-2'-deoxycytidine. Nucleic Acid Res Spec Publ 4:109-113

37. Pohlmann P, DiLeone LP, Cancella AI et al (2002) Phase II trial of cisplatin plus decitabine, a new DNA hypomethylating agent, in patients with advanced squamous carcinoma of the cervix. Am J Clin Oncol 25:496-501

38. Ravandi F, Kantarjian H, Cohen A, Davis M, O'Brien S, Anderlini P, Andersson B, Claxton D, Donato M, Gajewski J, Khouri I, Korbling M, Ueno N, deVos D, Champlin R, Giralt S (2001) Decitabine with allogenic peripheral blood stem cell transplantation in the therapy of leukaemia relapse following a prior transplant: results of a phase I study. Bone Marrow Transplant 27:1221-1225

39. Richel DJ (1990) Experimental therapy in Ara-C sensitive and resistant leukaemia, Ph.D. thesis. University of Leiden. The Netherlands

40. Richel DJ, Colly LP, Kluin-Nelemans JC, Willemze R (1991) The antileukaemic activity of 5-aza-2'-deoxycytidine (Aza-dC) in patients with relapsed acute leukaemia. Br J Cancer 64: 144-148
41. Rivard GE, Momparler RL, Demers J et al (1981) Phase I study on 5-aza-2'-deoxycytidine in children with acute leukemia. Leuk Res 5:453-462

42. Ruter B, Wijermans PW, Lübbert M (2004) DNA methylation as a therapeutic target in hematologic disorders: recent results in older patients with myodysplasia and acute myeloid leukaemia. Int J Hematol 80:128-135

43. Sachs L (1978) The differentiation of myeloid leukaemia cells: new possibilities for therapy. Br J Haematol 40:509-517

44. Schwartsmann G, Schunemann H, Gorini CN et al (2000) A phase I trial of cisplatin plus decitabine, a new DNAhypomethylating agent, in patients with advanced solid tumors and a follow-up early phase II evaluation in patients with inoperable non-small cell lung cancer. Invest New Drugs 18:83-91

45. Sessa C, Ten Bokkel Huinink W, Stoter G, Renard J, Cavalli F (1990) Phase II study of 5-aza-2'-deoxycytidine in advanced ovarian cancer. Eur J Cancer 26:137-138

46. Sorm F, Vesely J (1968) Effect of 5-aza-2'-deoxycytidine against leukemic and hemopoietic tissues in AKR mice. Neoplasma 15:339-343

47. Thibault A, Figg WD, Bergan RC et al (1998) A phase II study of 5-aza-2'-deoxycytidine (decitabine) in hormone independent metastatic (D2) prostate cancer. Tumori 84:87-89

48. van Groeningen CJ, Leyva A, O'Brien AM, Gall HE, Pinedo HM (1986) Phase I and pharmacokinetic study of 5-aza-2'deoxycytidine (NSC 127716) in cancer patients. Cancer Res 46:4831-4836

49. Vermorken JB, Tumolo S, Roozendaal KJ, Guastalla JP Splinter TA, Renard J (1991) 5-Aza-2'-deoxycytidine in advanced or recurrent cancer of the cervix. Eur J Cancer 27: $216-217$

50. Wijermans P, Lübbert M, Verhoef G et al (2000) Low-dose 5-aza-2'-deoxycytidine, a DNA hypomethylating agent, for the treatment of high-risk myelodysplastic syndrome: a multicenter phase II study in elderly patients. J Clin Oncol 18:956-962

51. Willemze R, Stegman APA, Colly LP (1990) The use of 5-aza2 '-deoxycytidine (DAC) in adult patients with acute leukaemia (abstr). Haematologica 76:43 